\title{
HUBUNGAN TINGKAT PENGETAHUAN KELUARGA DALAM MENINGKATKAN KETERAMPILAN KELUARGA UNTUK MENSTIMULASI TUMBUH KEMBANG BALITA USIA 2-5 TAHUN
}

\author{
Yudha Jatmika ${ }^{1}$, Puspa Fitriyana ${ }^{2}$, Jamilatul Komari ${ }^{3}$, Chairun Nisak ${ }^{4 *}$, Novaria \\ Puspitasari $^{5}$, Novita Nurkamilah ${ }^{6}$, Siti Aisyah Asri ${ }^{7}$, Mayangga Sukmawati ${ }^{8}$, Hanny \\ Rasni $^{9}$ \\ 1,2,3,4,5,6,7,8,9 Fakultas Keperawatan Universitas Jember \\ J1. Kalimantan No. 37 Kampus Tegal Boto Jember Telp./Fax. (0331) 323450 \\ *e-mail: chairunnisak.78@gmail.com
}

\begin{abstract}
ABSTRAK
Tumbuh kembang anak berlangsung secara teratur, saling berkaitan dan berkesinambungan dimulai sejak konsepsi hingga dewasa. Dasar kepribadian anak terbentuk dari keluarga dan lingkungan. Tujuan penelitian ini adalah untuk mengetahui tingkat pengetahuan ibu tentang tumbuh kembang balita usia 2-5 tahun. Tujuan khusus untuk mengetahui tingkat pengetahuan keluarga balita tentang tumbuh kembang balita umur 2-5 tahun di Desa Serut pada tingkat baik, cukup, kurang dan mengetahui faktor yang mempengaruhi pengetahuan keluarga tentang tumbuh kembang balita umur 2-5 tahun. Penelitian observasional dengan pendekatan cross sectional, dimana data yang menyangkut variabel bebas dan variabel terikat diambil dalam waktu yang bersamaan, dengan tujuan untuk mencari hubungan antara dua variable. Berdasarkan analisa bivariat diperoleh $p$-value $=0,002(\alpha \leq 0,05)$ yang artinya ada hubungan antara hubungan tingkat pengetahuan keluarga dalam meningkatkan keterampilan keluarga untuk menstimulasi tumbuh kembang balita. Nilai koefisien korelasi yang didapatkan pada analisis bivariat yaitu 0,373 yang menunjukkan bahwa arah korelasi positif dengan kekuatan korelasi antara kedua variabel dalam kategori sedang.

Kata kunci: tingkat pengetahuan, keterampilan, tumbuh kembang balita
\end{abstract}

\section{ABSTRACT}

Child growth takes place regularly, interconnected and sustainable starting from conception to adulthood. The basic personality of the child is made up of family and environment. The purpose of this study is to determine the level of knowledge of the mother about the growth of toddlers aged 2-5 years. Specific Objective to know the level of knowledge of toddlers about toddler growth of 2-5 years old in Serut Village at good level, enough, less and know the factors that influence the family knowledge about the growth of toddlers aged 2-5 years. Observational research with cross sectional approach, where data concerning independent variables and dependent variables are taken at the same time, with the aim to find the relationship between two variables. Based on bivariate analysis obtained $p$-value $=0,002(\alpha \leq 0,05)$ which means there is relationship between relation of family knowledge level in improving family skill to stimulate growth of toddler. The correlation coefficient value obtained in bivariate analysis is 0.373 which shows that the direction of positive correlation with the correlation strength between the two variables in the medium category.

Keywords: level of knowledge, skills, growth and development of children under five 


\section{PENDAHULUAN}

Anak merupakan dambaan keluarga. Setiap keluarga mengharapkan anak yang mampu tumbuh dan berkembang secara optimal, baik secara fisik, mental, kognitif maupun sosial, serta berguna bagi nusa dan bangsa. Sebagai aset bangsa, anak harus mendapat perhatian sejak mereka masih didalam kandungan sampai mereka menjadi manusia dewasa. Periode penting dalam tumbuh kembang anak adalah pada usia di bawah lima tahun. Balita yang berusia 3-5 tahun dikategorikan ke dalam masa kanakkanak awal. Pada tahap ini keterampilan dan kemandirian anak perlu diperhatikan, khususnya oleh orang tua terutama ibu. Ibu perlu memiliki dan mengetahui keterampilan sesuai dengan tahap perkembangan anaknya. Pada tahun 2007 sekitar 35,4\% anak balita di Indonesia menderita penyimpangan perkembangan seperti penyimpangan dalam motorik kasar, motorik halus, serta penyimpangan mental emosional.

Kemampuan, keterampilan, serta peranan ibu sangat bermanfaat bagi proses perkembangan dan pertumbuhan anak secara keseluruhan karena orang tua dapat segera mengenali kelebihan proses perkembangan anaknya dan sedini mungkin dapat memberikan stimulasi pada tumbuh kembang anak yang menyeluruh dalam aspek fisik, mental, dan sosial. Rangsangan atau stimulasi dalam keluarga dapat berupa penyediaan alat mainan, sosialisasi anak, keterlibatan ibu dan anggota keluarga lain terhadap kegiatan anak. Peranan stimulasi akan dipengaruhi oleh berbagai faktor, salah satu faktor yang terpenting adalah faktor ibu atau pengasuh tetap, karena ibu atau pengasuh tetap yang menentukan berhasil atau hanya lewat saja perkembangan anak.

Berdasarkan hasil penjajakan di Desa Serut Kecamatan Panti Kabupaten Jember didapatkan jumlah ibu-ibu yang mempunyai balita yang berumur 2-5 tahun di Desa Serut sebanyak 23 orang. Hasil wawancara dari tujuh ibu yang memiliki balita mengatakan belum pernah diajarkan tentang bagaimana cara menstimulasi dan keterampilan apa yang mereka berikan pada anaknya. Para ibu yang memiliki balita belum pernah diberikan penyuluhan tentang tumbuh kembang anak. Berdasarkan latar belakang diatas maka rumusan masalah dalam penelitian ini adalah "Apakah ada hubungan tingkat pengetahuan keluarga dalam meningkatkan keterampilan keluarga untuk menstimulasi tumbuh kembang balita usia 2-5 tahun?".

Pengetahuan adalah merupakan hasil mengingat suatu hal, termasuk mengingat kembali kejadian yang pernah dialami baik secara sengaja maupun tidak disengaja dan ini terjadi setelah orang melakukan kontak atau pengamatan terhadap suatu objek tertentu.

Pengetahuan yang dicakup dalam domain kognitif mempunyai enam tingkatan yaitu Tahu (Know), Memahami (Comprehention), Aplikasi (Application), Analisis (Analysis), Sintesis (Synthesis), Evaluasi (Evaluation). Sedangkan menurut Mubarak (2007), faktor-faktor yang mempengaruhi pengetahuan seseorang adalah pendidikan, Pekerjaan, Umur, Minat, Pengalaman, Kebudayaan lingkungan sekitar, dan informasi.

Pertumbuhan (growth) berkaitan dengan masalah perubahan dalam besar jumlah, ukuran atau dimensi tingkat sel, organ maupun individu, yang bisa diukur dengan ukuran berat (gram, pound, kilogram), ukuran panjang (cm, meter), umur tulang dan keseimbangan metabolik (retensi kalsium dan nitrogen tubuh). Sedangkan perkembangan adalah bertambahnya sempurnanya fungsi alat tubuh yang dapat dicapai melalui tumbuh kematangan dan belajar.

Kebutuhan dasar anak untuk tumbuh kembang, secara umum di golongkan 
menjadi tiga kebutuhan dasar, yaitu pertama Kebutuhan fisik biomedis (Asuh) yang terdiri dari Pangan/gizi, Perawatan kesehatan dasar: imunisasi, pemberian ASI, penimbangan yang teratur dan pengobatan., Pemukiman yang layak, Kebersihan perorangan dan sanitasi lingkungan, Pakaian, dan Rekreasi dan kebugaran jasmani. Kedua, Kebutuhan emosi dan kasih sayang (Asih) dan yang ketiga Kebutuhan akan stimulasi mental (Asah) yaitu kecerdasan, ketrampilan, kemandirian, kreativitas, agama, kepribadian, produktivitas dan sebagainya. Anak yang mendapat asuh, asih, dan asah yang memadai akan mengalami tumbuh kembang yang optimal sesuai dengan potensi genetik yang dimilikinya.

Aspek-aspek perkembangan yang dipantau adalah perkembangan kemampuan gerak kasar, Perkembangan kemampuan gerak halus, Perkembangan kemampuan bicara, bahasa, dan kecerdasan, serta Perkembangan kemampuan bergaul dan mandiri.

Perkembangan anak terdapat 4 parameter perkembangan melalui melalui DDST (Denver Developmental Screening Test) yang dipakai dalam menilai perkembangan balita yaitu Personal social development (kepribadian/tingkah laku sosial, Gross motor development (gerakan motorik kasar), Fine motot development (gerakan motorik halus), Language development (perkembangan bahasa).

Pertumbuhan fisik adalah hasil dari perubahan bentuk dan fungsi dari organisme. Pertumbuhan Fisik Balita Usia 2-5 tahun dibagi menjadi 2 bagian yaitu Pertumbuhan janin intrauterin, Pertumbuhan setelah lahir (berat badan, tinggi badan, kepala, gigi, jaringan lemak, organ-organ tubuh).

Tahapan perkembangan mental, gerakan-gerakan kasar \& halus, emosi, sosial perilaku, bicarayang meliputi Usia 2-3 tahun (Motorik Halus: Menggambar lingkaran dan Motorik kasar: Belajar meloncat, memanjat melompat dengan satu kaki, Bermain bersama dengan anak lain dan menyadari adanya lingkungan lain diluar keluarganya serta Bahasa: Mampu menyusun kalimat, Mempergunakan katakata saya, bertanya, mengerti kata- kata yang ditujukan kepadanya). Usia 3-4 tahun (Motorik halus: Menggambar garis silang, Mengenal 2 atau 3 warna. Motorik kasar: Belajar berpakaian dan membuka pakaian sendiri, bermain dengan anak lain, dapat melaksanakan tugas-tugas sederhana. Bahasa: Banyak bertanya, Bicara dengan baik, Menyebut namanya, jenis kelamin dan umurnya). Usia 4-5 tahun (Motorik halus: Menggambar segi empat dan segitiga, Menggambar orang terdiri dari kepala, lengan, badan. Motorik kasar: Melompat dan menari, Menaruh minat kepada aktivitas orang dewasa. Bahasa: Minat kepada kata baru dan artinya, Pandai bicara, Mendengar dan mengulang hal-hal penting dan cerita).

\section{METODE}

Penelitian ini adalah penelitian observasional dengan pendekatan cross sectional, dimana data yang menyangkut variabel bebas dan variabel terikat diambil dalam waktu yang bersamaan, dengan tujuan untuk mencari hubungan antara dua variabel. Adapun variabel bebas dari penelitian ini adalah pengetahuan orang tua tentang stimulasi, sementara variabel terikat dari penelitian ini adalah perkembangan anak usia 2-5 tahun.

\section{HASIL}

\section{Karakteristik Demografi}

Penyajian hasil penelitian meliputi analisis univariat dan bivariat. Analisis univariat dalam bentuk distribusi frekuensi meliputi umur, jenis kelamin, pendidikan, pekerjaan, sedangkan analisis bivariat untuk melihat hubungan tingkat pengetahuan keluarga dalam meningkatkan keterampilan 
keluarga untuk menstimulasi tumbuh kembang balita usia 2-5 tahun.

\section{Karakteristik Responden}

Tabel 1. Rerata Karakteristik Usia Ibu di Desa Serut Kecamatan Panti

\begin{tabular}{lll}
\hline Karakteristik & $\begin{array}{l}\text { Frekuensi } \\
\text { (Orang) }\end{array}$ & $\begin{array}{l}\text { Presentase } \\
(\boldsymbol{\%})\end{array}$ \\
\hline 28 tahun & 2 & 40 \\
29 tahun & 1 & 20 \\
30 tahun & 1 & 20 \\
32 tahun & 1 & 20 \\
\hline Total & $\mathbf{5}$ & $\mathbf{1 0 0}$ \\
\hline
\end{tabular}

Berdasarkan tabel di atas dapat dijelaskan bahwa hampir setengah umur ibu berusia 28 tahun dan didapatkan sebanyak

Tabel 2. Distribusi Pendidikan Ibu di Desa Serut Kecamatan Panti Tahun 2018

\begin{tabular}{lll}
\hline Pendidikan & $\begin{array}{l}\text { Frekuensi } \\
\text { (Orang) }\end{array}$ & $\begin{array}{l}\text { Presentase } \\
(\boldsymbol{\%})\end{array}$ \\
\hline SD & 3 & 60 \\
SMP & 2 & 40 \\
SMA & 0 & 0 \\
PT & 0 & 0 \\
\hline Total & $\mathbf{5}$ & $\mathbf{1 0 0}$ \\
\hline
\end{tabular}

Berdasarkan tabel distribusi di atas dapat dijelaskan bahwa sebagian besar pendidikan ibu SD didapatkan sebanyak 3(60\%)ibu, dan sebagian kecil adalah SMP sebanyak 2 (40\%) ibu.

Tabel 3. Distribusi Pekerjaan Orangtua di Desa Serut Kecamatan Panti

\begin{tabular}{lll}
\hline Pekerjaan & $\begin{array}{l}\text { Frekuensi } \\
\text { (Orang) }\end{array}$ & $\begin{array}{l}\text { Presentase } \\
(\boldsymbol{\%})\end{array}$ \\
\hline Buruh & 0 & 0 \\
IRT & 5 & 100 \\
Swasta & 0 & 0 \\
Wiraswasta & 0 & 0 \\
\hline Total & $\mathbf{5}$ & $\mathbf{1 0 0}$ \\
\hline
\end{tabular}

Berdasarkan tabel distribusi di atas dapat dijelaskan bahwa sebagian besar pekerjaan Ibu adalah IRT didapatkan sebanyak 5 (100\%) ibu.

Tabel 4. Distribusi Umur Anak di Desa Serut Kecamatan Panti

\begin{tabular}{lll}
\hline Umur Anak & $\begin{array}{l}\text { Frekuensi } \\
\text { (Orang) }\end{array}$ & $\begin{array}{l}\text { Presentase } \\
(\boldsymbol{\%})\end{array}$ \\
\hline 2 tahun & 2 & 40 \\
3 tahun & 3 & 60 \\
4 tahun & 0 & 0 \\
5 tahun & 0 & 0 \\
\hline Total & $\mathbf{5}$ & $\mathbf{1 0 0}$ \\
\hline
\end{tabular}

Berdasarkan tabel distribusi di atas dapat di jelaskan bahwa sebagian besar anak berumur 3 tahun sebanyak $3(60 \%)$ dan sebagian kecil berumur 2 tahun.

Tabel 5. Ditribusi Hubungan Tingkat Pengetahuan Keluarga dalam Meningkatkan Keterampilan Keluarga untuk Menstimulasi Tumbuh Kembang Balita Usia 2-5 tahun

\begin{tabular}{llcc}
\hline \multicolumn{1}{c}{ Variabel } & n & r & P \\
\hline hubungan & 5 & 0,373 & 0,002 \\
tingkat & & & \\
pengetahuan & & & \\
keluarga dalam & & & \\
meningkatkan & & & \\
keterampilan & & & \\
keluarga untuk & & \\
menstimulasi & & \\
tumbuh & & \\
kembang balita & & \\
usia 2-5 tahun &
\end{tabular}

Berdasarkan analisa bivariat tabel diatas diperoleh $\mathrm{p}$-value $=0,002(\alpha \leq 0,05)$ yang artinya ada hubungan antara hubungan tingkat pengetahuan keluarga dalam meningkatkan keterampilan keluarga untuk menstimulasi tumbuh kembang balita. Nilai 
koefisien korelasi yang didapatkan pada analisis bivariat yaitu 0,373 yang menunjukkan bahwa arah korelasi positif dengan kekuatan korelasi antara kedua variabel dalam kategori sedang. Hal ini dikatakan arah korelasi negatif dimana apabila salah satu variabel naik maka variabel kedua turun. Penelitian ini didapatkan bahwa apabila tingkat pengetahuan keluarga baik maka stimulasi perkembangan anak baik dan sebaliknya.

\section{PEMBAHASAN}

Berdasarkan tabel di atas, dapat diketahui bahwa ada hubungan antara pengetahuan tentang stimulasi dengan perkembangan anak pra sekolah di Desa Serut Kecamatan Panti. Hasil penelitian ini selaras dengan penelitian yang dilakukan oleh Sari (2011), yang menunjukkan ada hubungan antara pengetahuan ibu dan perkembangan motorik kasar anak usia 3-5 tahun di PAUD Ngudi Rahayu Desa Lerep Kecamatan Ungaran Barat Kabupaten Semarang. Hubungan ini mempunyai arah yang positif artinya semakin baik pengetahuan ibu maka semakin baik perkembangan motorik kasar anak usia $3-5$ tahun.

Pengetahuan ibu yang baik akan memberikan hasil yang baik, artinya dengan adanya pengetahuan ibu yang baik tentang pemberian stimulasi motorik kasar maka perkembangan anak terhadap motorik kasarnya akan baik pula. Begitu pula sebaliknya, pengetahuan ibu yang kurang akan memberikan efek yang kurang baik terhadap anak. Anak yang diasuh oleh orangtua yang berpendidikan rendah memiliki risiko tiga kali mengalami keterlambatan perkembangan dibandingkan orang tua yang berpendidikan tinggi (Ariani \& Yosoprawoto, 2012).

Menurut Baker dan Lopez (2010) pengetahuan yang diperoleh dari pendidikan,di mana semakin tinggi pendidikan seseorang maka dapat memberikan pengetahuan lebih baik dibandingkan mereka yang berpendidikan rendah, sehingga yang berpengetahuan lebih baik akan semakin paham dengan materi, strategi serta mampu dalam menerapkan apa yang diketahui, dalam hal ini paham dengan materi stimulasi perkembangan motorik kasar sehingga para keleuarga mampu menerapkan langsung untuk memberi rangsangan perkembangan kepada anaknya. Berdasarkan hasil penelitian yang dilakukan oleh Ariyana (2009) di mana terdapat hubungan yang signifikan antara pengetahuan ibu dengan perkembangan motorik kasar dan halus pada anak usia 4-5 tahun.

Menurut asumsi peneliti, berdasarkan hasil penelitian yang telah dilakukan, mayoritas responden yang berpengetahuan kurang baik dilatarbelakangi dengan pendidikan terakhir SD. Selain dari tingkat pendidikan, pengetahuan orangtua juga dapat dipengaruhi oleh media masa, hubungan sosial dan pengalaman. Dari segi pekerjaan mayoritas berprofesi sebagai Ibu Rumah Tangga, di mana untuk memenuhi kebutuhan setiap hari, kebanyakan dari mereka melakukan aktivitas jauh dari paparan media masa, kurangnya pengalaman dan interaksi sosial dengan orang-orang berpengetahuan tentang pentingnya stimulasi dini terhadap perkembangan anak. Berdasarkan analisa di atas diperoleh kesimpulan bahwa pengetahuan ibu tentang pemberian stimulasi sangat berpengaruh terhadap perkembangan.

Berdasarkan tabel di atas, dapat diketahui ada hubungan antara pengetahuan ibu tentang pemberian stimulasi dengan perkembangan anak pra sekolah di Desa Serut. Stimulasi atau rangsangan sangat dibutuhkan guna memaksimalkan seluruh potensi yang dimiliki oleh anak sejak masih dalam kandungan. Ketika anak lahir 
rangsangan harus dilakukan terus-menerus, bervariasi, serta dengan suasana bermain dan kasih sayang sebab, rangsangan yang diberikan oleh orangtua dengan banyak cara dapat menstimulasi seluruh potensi yang dimiliki oleh anak (Fida \& Maya, 2012).

Hasil penelitian Reni (2011) di TK Dharma Wanita Lor Kecamatan Bandung tentang hubungan pola asuh orang tua dengan perkembangan motorik halus anak menunjukkan dukungan dari orang-orang di sekitar, terlebih orang tua sebagai pengasuh memiliki peran yang sangat besar terhadap perkembangan anak usia pra sekolah

Menurut asumsi peneliti, anak usia pra sekolah perlu mendapatkan stimulasi perkembangan motorik halus yang baik. Hal ini juga dapat dilihat berdasarkan hasil wawancara peneliti bahwa sebagian ibu kurang memahami tentang cara menstimulus perkembangan anaknya. Sebagian ibu menganggap anak tidak perlu diberikan stimulasi perkembangan seperti perkembangan motorik halus karena tanpa diberikan stimulasi anak juga akan bisa berkembang dengan baik. Orang tua sebagai pengasuh memiliki peranan penting dalam mengontrol, membimbing dan mendampingi anak- anaknya menuju kedewasaan. Dalam menuju kedewasaan, orang tua memiliki kewajiban untuk memenuhi apa yang menjadi hak-hak anak. Untuk itu, pengetauan yang baik merupakan hal yang perlu dicapai karena dapat menjadi salah satu faktor pendukung stimulasi terhadap perkembangan motorik anak. Berdasarkan tabel di atas, dapat diketahui bahwa ada hubungan antara pengetahuan ibu tentang pemberian stimulasi dengan perkembangan anak pra sekolah di Desa Serut Kecamatan Panti.

\section{KESIMPULAN}

Terdapat

hubungan antara pengetahuan ibu tentang stimulasi dengan perkembangan anak pra sekolah di Desa Serut Kecamatan Panti.

\section{SARAN}

Diharapkan bagi masyarakat khususnya ibu, agar melakukan pemberian stimulasi, deteksi dan intervensi sedini mungkin terhadap perkembangan anak pra sekolah sesuai dengan usianya.

Bagi peneliti selanjutnya, agar membuat penelitian lebih lanjut dalam bentuk metode penelitian atau desain penelitian bersifat eksperimental dengan jumlah sampel yang lebih banyak sehingga hasilnya lebih akurat dan dapat dijadikan bahan referensi untuk penelitian lanjutan dalam bentuk yang lebih kompleks yang berhubungan dengan pengetahuan ibu tentang pemberian stimulasi dengan perkembangan anak pra sekolah.

Penelitian ini memberikan pemahaman baru Bagi keluarga dan masyarakat sehingga diharapkan dapat digunakan sebagai sarana informasi, dan menambah keterampilan dalam menstimulasi tumbuh kembang anak dan dapat disebarluaskan.

Bagi profesi perawat diharapkan sebagai salah satu masukan bagi perawat dalam upaya meningkatkan kualitas pelayanan kesehatan yang optimal berupa pemantauan, memberikan informasi stimulasi tumbuh kembang pada anak.

Bagi peneliti lain diharapkan dengan penelitian ini dapat melanjutkan penelitian berupa pembuatan modul stimulasi bagi ibu untuk meningkatkan ketrampilan dan pengetahuan tentang tumbuh kembang dan menambah sampel penelitian agar hasil penelitian digeneralisasikan tidak sebatas pada satu desa yang diteliti.

\section{UCAPAN TERIMA KASIH}

Penulis menyampaikan terima kasih kepada seluruh responden, dosen 
pembimbing, dan pihak Desa Serut Kecamatan Panti, Kabupaten Jember.

\section{KEPUSTAKAAN}

Adriana, D. 2013. Tumbuh Kembang dan Terapi Bermain Pada Anak .Salemba Medika : Jakarta

Anwar, H. 2013. Analisa Dampak Penggunaan Modul Terhadap Peningkatan Pengetahuan Dan Keterampilan Keluarga Dalam Menstimulasi Tumbuh Kembang Bayi. Jurnal Stikes Harapan Bangsa Volume 2. No, 1 : 12-24

Ariyana, R. 2009. Hubungan Pengetahuan lbu Tentang perkembangan Anak Dengan Perkembangan Motorik Kasar Dan Motorik Halus Anak Usia 4-E Tahun Di Tl Aisyiyah Bustanul Athfal 7 Semarang. Jurnal Stikes Widya Husada Semarang Volume 2. No, 2 : 11-20

Departemen Kesehatan RI. 2009. Pedoman Pelaksanaan Stimulasi, Deteksi, Dan Intervensi Dini Tumbuh Kembang Anak Ditingkat Pelayanan Kesehatan Dasar. Bakti Husada: Jakarta.

Fida \& Maya. (2012). Pengantar Ilmu Kesehatan Anak. Jogjakarta: DMedika
Hariweni, T. 2006. Hubungan Pengetahuan, Sikap dan Keterampilan Ibu Bekerja dan Tidak Bekerja Tentang Stimulasi Pada Pengasuhan Anak Balita. Jurnal Universitas Sumatra Utara Volume 5. No, $1: 82-97$

Kania, N. (2007). Stimulasi tumbuh kembang anak untuk mencapai tumbuh kembang yang optimal.Diperoleh pada tanggal 8 Juni 2018 dariwww.pustaka.unpad.ac.id.

Notoatmodjo, S. 2012. Metodologi Penelitian Kesehatan. PT Rineka Cipta: Jakarta

Putra, Setiawan,D. 2014. Keperawatan Anak dan TUmbuh Kembang. Melia Medika :Yogyakarta

Reni. (2011). Hubungan pola asuh dengan perkembangan anak. Diperoleh pada tanggal 30 Mei 2018 dari www.pustaka.unpad.ac.id

Soedjatmiko. 2008. Stimulasi Dini pada Bayi dan Balita. Available from http://14str1.multiply.com/reviews/ite $\underline{\mathrm{m} / 5}$. [diakses 28 Mei 2018]

Sulistyawati. 2014. Deteksi Tumbuh Kembang Anak. Salemba Medika: Jakarta 